\title{
Concordance between needle biopsy and radical prostatectomy specimens in prostatic carcinoma
}

\section{Prostat kanserinde iğne biyopsi ve radikal prostatektomi örnekleri arasındaki uyum}

\author{
Cevahir Özer'1, Bermal Hasbay² \\ ${ }^{1}$ Başkent Üniversitesi Adana Dr. Turgut Noyan Uygulama Ve Araştırma Merkezi, Üroloji Bölümü, Adana \\ ${ }^{2}$ Başkent Üniversitesi Adana Dr. Turgut Noyan Uygulama Ve Araştırma Merkezi, Patoloji Bölümü, Adana
}

Dergiye Ulaşma Tarihi: 01.10.2020 Dergiye Kabul Tarihi: 16.11.2020 Doi: 10.5505/aot.2020.36459

GİRIŞ ve AMAÇ: Bu çalıșmada prostat kanseri nedeniyle radikal prostatektomi uyguladığımız hastalarımızda iğne biyopsisi örnekleri ile radikal prostatektomi örnekleri arasındaki uyumu değerlendirmeyi amaçladık. YÖNTEM ve GEREÇLER: Retrospektif çalışmada, Kasım 2010 - Mayıs 2020 tarihleri arasında prostat kanseri nedeniyle radikal prostatektomi yapılan 167 erkek hasta değerlendirildi. Patolojik tanıları merkezimizde yapılan iğne biyopsisi ile konulan ve radikal prostatektomi öncesi prostat kanserine yönelik herhangi bir tedavi almamış hastalar çalışmaya dahil edildi. İğne biyopsileri dış merkezde yapılan 92 hasta, patolojik tanıları transüretral rezeksiyon materyali ile konulan 2 hasta ve radikal prostatektomi öncesinde hormonoterapi alan 1 hasta ile radyoterapi alan 1 hasta çalışma dışı bırakıldı.

BULGULAR: Çalışmaya dahil edilen toplam 71 hastanın yaş ortalaması $62.3 \pm 6.0$ (aralık, 46 - 75) yıl, tanı öncesi ortalama PSA düzeyi ise $10.0 \pm 7.6$ (aralık, $3.2-48.1) \mathrm{ng} / \mathrm{mL}$ idi. 31 (\%43.7) hastada parmakla rektal muayenede şüpheli bulgu mevcuttu.

İğne biyopsisi örnekleri ile radikal prostatektomi örnekleri arasındaki Gleason skoru, prognostik grup ve tümör lateralitesi açısından uyum sırasıyla \%66.2, \%59.2 ve \%74.6 idi.

TARTIŞMA ve SONUÇ: Prostat kanseri tanısı konulan hastalarda iğne biyopsisi örneklerinin patolojik değerlendirmesi tedavi yöntemlerinin belirlenmesinde kritik role sahiptir. Bununla birlikte, iğne biyopsisi örneklerinin prostat patolojisini yüksek bir uyumla öngörmediği akılda tutulmalıdır.

Anahtar Kelimeler: prostat kanseri, prostat biyopsisi, prostatektomi

\begin{abstract}
INTRODUCTION: In this study, we aimed to evaluate the concordance between needle biopsy samples and radical prostatectomy samples in our patients who underwent radical prostatectomy for prostate cancer.

METHODS: In this retrospective study, 167 male patients who underwent radical prostatectomy for prostate cancer between November 2010 and May 2020 were evaluated. Patients whose pathological diagnoses were made by needle biopsy at our center and who did not receive any treatment for prostate cancer before radical prostatectomy were included in the study. 92 patients whose needle biopsies were performed in a different center, 2 patients whose pathological diagnosis was made with transurethral resection material, 1 patient who received hormonotherapy before radical prostatectomy and 1 patient who received radiotherapy were excluded. RESULTS: The mean age of 71 patients included in the study was $62.3 \pm 6.0$ (range, 46 - 75) years, and the mean PSA level before diagnosis was $10.0 \pm 7.6$ (range, $3.2-48.1$ ) $\mathrm{ng} / \mathrm{mL}$. Suspicious findings were found on digital rectal examination in $31(43.7 \%)$ patients.

The concordance between needle biopsy samples and radical prostatectomy samples was $66.2 \%, 59.2 \%$ and $74.6 \%$, respectively, in terms of Gleason score, prognostic group and tumor laterality.

DISCUSSION AND CONCLUSION: Pathological evaluation of needle biopsy samples has a critical role in determining the treatment methods in patients diagnosed with prostate cancer. However, it should be borne in mind that needle biopsy specimens do not predict prostate pathology with high concordance.
\end{abstract}

Keywords: prostate cancer, prostate biopsy, prostatectomy

\section{GíRiş}

Prostat kanseri erkeklerde en s1k görülen ikinci kanserdir ve kansere bağlı ölümlerde altıncı sırada yer almaktadır (1). İleri yaş, ırksal farklılık, genetik faktörler ve aile öyküsü prostat kanseri için bilinen risk faktörleridir (2). Bunların dışında, diyetle ilişkili faktörler, 
obezite ve sedanter yaşam tarzı, inflamasyon ve enfeksiyonlar, hiperglisemi, kimyasal madde ve iyonizan radyasyon maruziyeti ile prostat kanseri gelişimi arasında ilişkili olduğuna dair yayınlar mevcuttur (3). Prostat kanseri tanıs1, anormal parmakla rektal muayene (PRM) bulgusuna veya yüksek prostat spesifik antijen (PSA) düzeyine dayanan klinik şüphe halinde yapilan transrektal ultrasonografi (TRUS) eşliğinde prostat biyopsisi ile konulmaktadır (4).

Prostat kanserinin prognozunun belirlenmesi ve tedavi seçimi temel olarak klinik evreleme, PSA düzeyi ve iğne biyopsisi örneğindeki histolojik derecelendirmeye dayanmaktadır (5). Tümörün histolojik derecelendirmesinde en yaygın yaygın kullanilan sistem Gleason tarafindan tanımlanan Gleason derecelendirme sistemidir (6). Gleason derecelendirme sistemi tedavi seçiminde ve prognozda önemli bir faktör olarak kabul edilse de iğne biyopisi örnekleri ile radikal prostatektomi örnekleri arasındaki uyumsuzluk klinik uygulamada sorun olmaya devam etmektedir $(7,8)$.

Bu çalışmada, prostat kanseri nedeniyle radikal prostatektomi uyguladığımız hastalarımızda iğne biyopsisi örnekleri ile radikal prostatektomi örnekleri arasındaki uyumu güncel literatür eşliğinde değerlendirmeyi amaçladık.

\section{GEREÇ ve YÖNTEM}

Retrospektif çalışmada, Kasım 2010 - Mayıs 2020 tarihleri arasinda prostat kanseri nedeniyle radikal prostatektomi yapılan 167 erkek hasta değerlendirildi. Patolojik tanıları merkezimizde yapılan iğne biyopsisi ile konulan ve radikal prostatektomi öncesi prostat kanserine yönelik herhangi bir tedavi almamış hastalar çalışmaya dahil edildi.

Tüm hastalardan biyopsi işlemi ve operasyon öncesi aydınlatılmış onam formu alındi. Prostat biyopsileri, antibiyotik proflaksisi altında, TRUS eşliğinde 18 Gauge kalınlığında iğne kullanılarak alındı. Tüm hastalara açık radikal retropubik prostatektomi uygulandı. Tüm iğne biyopsi ve prostatektomi örneklerinin Gleason skoru, 2005 y1lında Uluslararasi Ürolojik Patoloji Derneği (ISUP) tarafindan alınan Gleason derecelendirme konsensüs kararlarına göre belirlendi (9).
Ayrica, Gleason skorları 2014 yılında ISUP tarafından kabul edilen ISUP derecelerine göre prognostik gruplara dönüştürüldü (10).

Yaş, iğne biyopsisi öncesi PSA düzeyi, PRM bulgusu, iğne biyopsisindeki örnek sayıs1, iğne biyopsisi örneğindeki ve prostatektomi örneğindeki patolojik tümör derecesi (Gleason skoru), prognostik grup, tümör tarafı ile patolojik tümör evresi belirlendi.

Bu çalışma Başkent Üniversitesi Tıp ve Sağlık Bilimleri Araştırma Kurulu tarafından onaylandı (Proje no: KA20/251) ve Başkent Üniversitesi Araştırma Fonu tarafından desteklendi.

\section{İstatistiksel analiz}

Verilerin istatistiksel analizinde SPSS 24.0 paket programı (SPSS Inc., Chicago, IL, USA) kullanıldı. Kategorik ölçümler sayı ve yüzde olarak, sürekli ölçümlerse ortalama ve standart sapma (gerekli yerlerde ortanca ve minimum maksimum) olarak özetlendi. İğne biyopsisi ve radikal prostatektomi örnekleri arasındaki ilişkiyi belirlemek için sınıf içi korelasyon testi uyguland. İğne biyopsisi ve radikal prostatektomi örnekleri arasındaki farkın karşılaştırılması için Bland-Altman uyum sınırları grafiği kullanıldı. Tüm testlerde istatistiksel önem düzeyi 0.05 olarak alındı.

\section{BULGULAR}

Çalışmaya dahil edilen toplam 71 hastanın yaş ortalaması $62.3 \pm 6.0$ (aralık, $46-75$ ) yıldı. İğne biyopsileri dış merkezde yapılan 92 hasta, patolojik tanıları transüretral rezeksiyon materyali ile konulan 2 hasta ve radikal prostatektomi öncesinde hormonoterapi alan 1 hasta ile radyoterapi alan 1 hasta çalışma dış1 bırakıldı. Çalışmaya dahil edilen hastaların klinik ve demografik özellikleri Tablo 1'de özetlenmiştir.

Hastaların iğne biyopsi ve prostatektomi örnekleri karşılaştırıldığında 24 (\%33.8) hastada Gleason skor değişimi (3 hastada azalma, 21 hastada artma), 29 (\%40.8) hastada ise prognostik grup değişimi (3 hastada azalma, 26 hastada artma) mevcuttu. Ayrica, 18 (\%25.4) hastada iğne biyopsisinde tek taraflı olan lezyon prostatektomi materyalinde iki taraflı tespit edildi. Hastaların patolojik tümör evre dağılımı $1(\% 1.4)$ hastada T1, 39 (\%54.9) T2 ve $31(\% 43.7)$ hastada ise T3 şeklindeydi. 
Hastaların patolojik özellikleri Tablo 2'de özetlenmiştir.

İğne biyopsisi ile radikal prostatektomi örneklerinin istatistiksel olarak değerlendirdiğimizde Gleason skor değişimi (sınıf içi korelasyon katsayısı 0.795; \%95 güven aralığında, $0.672-0.872$ ), prognostik grup (sınıf içi korelasyon katsayısı 0.84 ; $\% 95$ güven aralığında, $0.743-0.90$ ) ve taraf açısından (Spearman korelasyon katsay1s1 0.546, $\mathrm{p}=0.0001$; Kappa katsayıs1 0.411, $\mathrm{p}=0.0001$ ) uyum anlamlı bulundu. İğne biyopsisi örnekleri ile radikal prostatektomi örnekleri arasında Gleason skor ve prognostik grup değișimleri arasında uyumun sınıf içi korelasyon katsayıları yüksek olmakla birlikte Bland - Altman grafiklerindeki güven aralıkları ile değerlendirildiğinde uyumun iyi olmadiğ 1 gözlemlendi (Resim 1 ve Resim 2). Yaş, PSA düzeyi, PRM bulgusu ve iğne biyopsi sayısı ile uyum arasında istatistiksel anlamlı ilişki mevcut değildi.

Tablo 1. Hastaların demografik özellikleri.

\begin{tabular}{|c|c|}
\hline Hasta sayısı, $n$ & 71 \\
\hline Yaş, yıl & $\begin{array}{l}62.3 \pm 6.0(\text { aralık, } 46 \\
75)\end{array}$ \\
\hline PSA düzeyi, $\mathrm{ng} / \mathrm{mL}$ & $\begin{array}{l}10.0 \pm 7.6(\text { aralık, } 3.2 \\
48.1)\end{array}$ \\
\hline \begin{tabular}{|l}
$\begin{array}{l}\text { Rektal muayene bulgusu, } \mathrm{n} \\
(\%) \\
\\
\end{array}$ \\
Var \\
Yok
\end{tabular} & $\begin{array}{l}31(\% 43.7) \\
40(\% 56.3)\end{array}$ \\
\hline Biyopsi kor sayısı, $n$ & $\begin{array}{l}18.1 \pm 5.0 \text { (aralık, } 7 \\
34)\end{array}$ \\
\hline
\end{tabular}

PSA: prostat spesifik antijen

Tablo 2. Hastaların patolojik özellikleri.

\begin{tabular}{|c|c|c|c|c|c|c|c|}
\hline & \multicolumn{6}{|c|}{ Prostatektomi Gleason skoru } \\
\hline & & 5 & 6 & 7 & 8 & 9 & Toplam \\
\hline \multirow{4}{*}{ 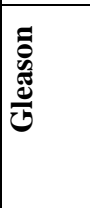 } & 5 & & & & & & \\
\hline & 6 & 1 & 20 & 16 & & & 37 \\
\hline & 7 & & 2 & 26 & 1 & 2 & 31 \\
\hline & 8 & & & & 1 & 2 & 3 \\
\hline \multirow{4}{*}{$\sum_{0}^{\bar{n}}$} & & & & & & & \\
\hline & Toplam & 1 & 22 & 42 & 2 & 4 & 71 \\
\hline & & \multicolumn{6}{|c|}{ Prostatektomi prognostik grup } \\
\hline & & 1 & 2 & 3 & 4 & 5 & Toplam \\
\hline 0 & 1 & 21 & 14 & 2 & & & 37 \\
\hline 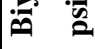 & 2 & 2 & 9 & 6 & 1 & 1 & 19 \\
\hline
\end{tabular}

\begin{tabular}{|c|c|c|c|c|c|c|c|}
\hline & 3 & & 1 & 10 & & \begin{tabular}{l|l}
1 & 1 \\
$\mid$
\end{tabular} & 12 \\
\hline & 4 & & & & 2 & 1 & \\
\hline & 5 & & & & & & \\
\hline & Toplam & 23 & 24 & 18 & 3 & 3 & 71 \\
\hline & & Pro & osta & tekt & om & i tara & \\
\hline & & Sağ & & Sol & & ateral & 1 Toplam \\
\hline & Sağ & 9 & & & 11 & & 20 \\
\hline$\Xi$ & Sol & & & 3 & 7 & & 10 \\
\hline$\frac{2}{0}$ & Bilatera & & & & 41 & & 41 \\
\hline 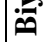 & Toplam & 9 & & 3 & 59 & & 71 \\
\hline
\end{tabular}

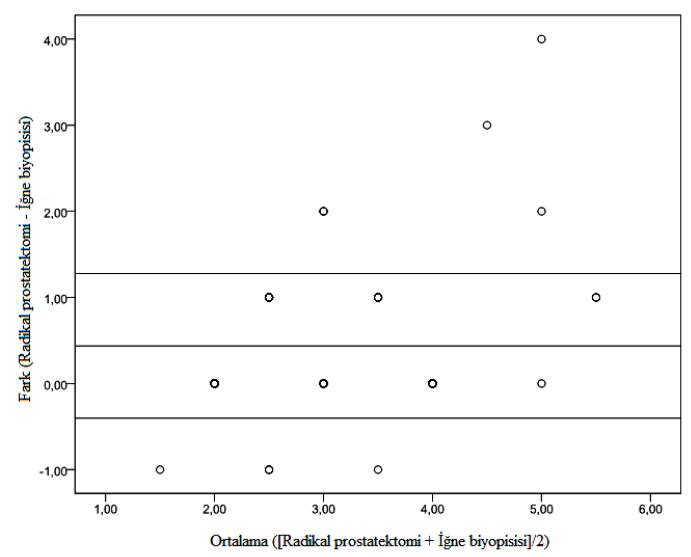

Resim 1. Gleason skoru için Blant - Altman uyum grafiği.

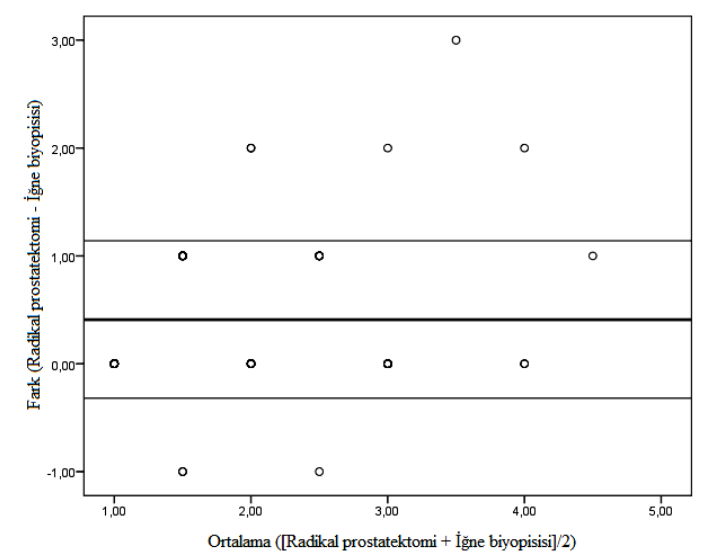

Resim 2. Prognostik grup için Blant - Altman uyum grafiği.

\section{TARTIŞMA}

Prostat kanserli hastalarda tedavi seçeneklerini tartışmak için yaş, komorbidite, PSA düzeyi ve PRM sonucu gibi klinik parametreler ile birlikte

Adress for correspondence: Dadaloğlu Mh. Serinevler 2591 Sk No: 4/a Yüreğir 01250 Adana - Türkiye Dr. Öğr. Üyesi Cevahir Özer e-mail: cevahirozer@gmail.com

Available at www.actaoncologicaturcica.com

Copyright $\odot$ Ankara Onkoloji Hastanesi 
patolojik parametreler (tümörün histolojik derecesi) hakkında doğru bilgiye sahip olmak gerekmektedir (5). Prostat kanserinin histolojik derecesi değerlendirmede kullanılan Gleason dereceleme sistemi en önemli prediktif parametrelerden birisi olarak kabul görmektedir ve klinisyen sadece iğne biyopsisi örneğinden elde edilen bilgileri kullanabilmektedir. Bununla birlikte, iğne biyopsisi örneği ile radikal prostatektomi örneği arasında uyum sorunu vardır. $\mathrm{Bu}$ sorun karşımıza skorlama (yüksek skorlama ve düşük skorlama) ve lateralite uyumsuzluğu şeklinde çıkmaktadır $(5,11)$.

İğne biyopsisindeki yüksek skorlama, hastalarda aktif tedavi seçeneklerinin tercih edilmesine ve dolayisiyla bir grup hastada gereksiz veya aşırı tedavilerin uygulanmasına yol açabilmektedir. İğne biyopsisinde düşük skorlama daha sık karşımıza çıkmaktadır ve hastanın radikal prostatektomi gibi bir küratif tedavi seçeneğinden mahrum kalmasına neden olabilmektedir. Ayrıca, lokalize prostat kanseri tedavisinde cerrahi tedavi dışındaki aktif tedavi seçenekleri olan eksternal radyoterapi, brakiterapi ve kriyoterapi gibi tedavilerde radikal prostatektomi örneğinden elde edilen gerçek bir Gleason skoru elde edilemeyeceği için, tedavi kararını kullanılan parametrelerden birisi olan iğne biyopsisindeki Gleason skoru daha önemli hale gelmektedir (12). İğne biyopisi örneği ile radikal prostatektomi örneği arasındaki uyum sorununda patolojik yorum, örnekleme hatası, alınan biyopsi sayısı ve biyopsi örneğindeki kanserli doku oranı gibi faktörler yer almaktadır $(5,13,14)$. Bu faktörlere biyopsi yöntemi de eklenmiş gibi görünmektedir. Füzyon biyopsilerin TRUS eşliğinde alınan biyopsilere göre radikal prostatektomi örnekleri ile uyumunun daha iyi olduğunu gösteren çalışmaların yanında benzer sonuçlara sahip olduğunu belirten yayınlar da mevcuttur $(15,16,17)$.

İğne biyopisisi örnekleri ile radikal prostatektomi materyali arasındaki Gleason skorlarının tutarlılığı \%28 ile \%68 arasında değişirken iğne biyopsisi örneklerinde düşük skorlama oranları $\% 22$ ile $\% 62$ arasında, yüksek skorlama oranları ise \%6 ile \%32 arasında bulunmuştur $(7,14,18)$. Bizim çalışmamızda tutarlılık oranı \%66.2 iken, düşük skorlama oranı \%29.6, yüksek skorlama oranı ise $\% 4.2$ idi. İğne biyopisisi örnekleri ile radikal prostatektomi materyali arasındaki uyumsuzluk literatür bilgisi ile uyumlu olacak şekilde düşük skorlamaya bağlıydı.

İğne biyopisisi örnekleri ile radikal prostatektomi materyali arasındaki uyumu prognostik grup açısından değerlendirdiğimizde ise tutarlığı $\% 56$ ile $\% 72$ arasında değiştiğini görmekteyiz $(7,19)$. Bizim çalışmamız ise bu oran $\% 59.2$ idi. \%36.6 oranında düşük skorlama, $\% 4.2$ oranında ise yüksek skorlama mevcuttu. Çalışmamızdan elde ettiğimiz bilgiler literatür ile uyumluydu.

Tümör lateralitesi açısından iğne biyopsisi örnekleri ile radikal prostatektomi örnekleri arasındaki uyumunu değerlendirmek fokal ablatif tedavi adaylarında iğne biyopsisi sonuçlarının tedavi planına etkisini değerlendirmek açısından önemli görünmektedir. Bununla birlikte, iğne biyopsilerinde tümör lateralitesi ile radikal prostatektomi örnekleri arasındaki korelasyonla ilgili çalışmalar sınırlıdır. Nepple ve ark. tarafindan yapilan ve 152 hastanın değerlendirildiği çalışmada bu oran $\% 51.3$ bulunmuştur (11). Bulbul ve ark. ise 100 hastay1 değerlendirdikleri çalışmalarında bu oranı $\% 53$ olarak bulmuşlardır (13). Pereira ve ark. tarafindan yapilan ve 191 hastanın değerlendirildiği çalışmada oran \%54 iken, Dell'Atti tarafından yapılan163 hastayı içeren çalışmada bu oran \%68.7'dir $(20,21)$. Bizim çalışmamızda ise, tümörün prostat içerisindeki lateralizasyonunu değerlendirmede uyumun \%74.6 oranında olduğunu görmekteyiz. Bizim serimizde bu oranın literatüre göre yüksek olması iğne biyopisi örneklerinde bilateral yerleşimli hasta oranını daha fazla olması ile ilişkili olabilir. İğne biyopsisi örneklerinde bilateral yerleşimli hasta oranı Nepple ve ark. tarafından yapılan çalışmada $\% 40.8$, Bulbul ve ark. tarafından yapılan çalışmada \%44 iken bizim çalışmamızda \%57.7 idi. Ayrıca, bizim serimizde ortalama biyopsi kor sayısı diğer çalışmalardan fazla olması dikkat çekicidir. Nepple ve ark. 6 ile 12 kor biyopsiyi karşılaştırırken, Bulbul ve ark. en az 12 kor biyopsi yaptıklarını belirtmişlerdir. Pereria ve ark. standart 12 kor biyopsi, Dell' Atti ise 14 kor biyopsi sonuçlarını bildirmiştir. Prostat kanserinde lateralitenin prognostik ve tanisal değeri üzerinde kesin bir sonuca ulaşmak için daha geniş analizleri içeren çalışmalara ihtiyaç varsa da tümörün lateralitesi $\mathrm{T}$ evresini 
etkilediğinden önemlidir (22). Ayrıca, iğne biyopsilerinin lateralite açısından radikal prostatektomi örnekleri ile tutarlığının yüksek olmaması fokal ablatif tedavilerin planlama sürecinde iğne biyopsisinin tek başına yeterli olmadığını düşündürmektedir. Fokal ablatif tedavi planlanan belirlenmesinde iğne biyopsilerinin multiparametrik prostat magnetik rezonans görüntüleme ile birlikte kombinasyonu doğru bir yaklaşım olarak karşımıza çıkmaktadır (23).

Çalışmamızın retrospektif ve hasta sayısının nispeten az olması temel dezavantajlarıdır. İğne biyopsisi örnekleri ile radikal prostatektomi örneklerinin üropatoloji alanında deneyimli bir patolog tarafindan değerlendirilmesi bir avantaj olsa da çalışmanın doğası gereği kör değerlendirme yapılamamış olması diğer bir dezavantaj olarak karşımıza çıkmaktadır.

Sonuç olarak, prostat kanseri tanısı konulan hastalarda iğne biyopsisi örneklerindeki patolojik değerlendirme hastaya önerilecek ve uygulanacak tedavi yöntemlerinin belirlenmesinde kritik role sahiptir. Bununla birlikte, iğne biyopsisi örneklerinin prostat patolojisini yüksek bir uyumla öngörmediği akılda tutulmalıdır.

\section{Conflict of interest:None}

\section{References}

1. Culp MB, Soerjomataram I, Efstathiou JA, Bray F, Jemal A. Recent Global Patterns in Prostate Cancer Incidence and Mortality Rates. Eur Urol 2020;77:38-52.

2. Gann PH. Risk factors for prostate cancer. Rev Urol 2002;4 Suppl 5:S3-S10.

3. Rawla P. Epidemiology of Prostate Cancer. World J Oncol 2019;10:63-89.

4. Kasivisvanathan V, Rannikko AS, Borghi M, et al. MRI-Targeted or Standard Biopsy for Prostate-Cancer Diagnosis. N Engl J Med 2018;378:1767-1777.

5. Divrik RT, Eroglu A, Sahin A, Zorlu F, Ozen H. Increasing the number of biopsies increases the concordance of Gleason scores of needle biopsies and prostatectomy specimens. Urol Oncol 2007;25:376-382.

6. Comperat E. Evolution of prostate cancer histopathology. Curr Opin Urol 2019;29:587592.

7. Gun BD, Bektas S, Bahadir B, Mungan A, Ozdamar SO. Comparison between needle biopsy and radical prostatectomy samples in assessing Gleason score and modified Gleason score in prostatic adenocarcinomas. Turk Patholoji Derg 2007;23:21-26.
8. Guner E, Simsek A. Preoperative and postoperative Gleason score correlation of patients who underwent radical prostatectomy. Bull Urooncol 2019;18:35-37.

9. Epstein JI, Allsbrook WC Jr, Amin MB, Egevad LL, Committee IG. The 2005 International Society of Urological Pathology (ISUP) Consensus Conference on Gleason Grading of Prostatic Carcinoma. Am J Surg Pathol 2005;29:1228-1242.

10. Epstein JI, Egevad L, Amin MB, et al. The 2014 International Society of Urological Pathology (ISUP) Consensus Conference on Gleason Grading of Prostatic Carcinoma: Definition of Grading Patterns and Proposal for a New Grading System. Am J Surg Pathol 2016;40:244-252.

11. Nepple KG, Wahls TL, Hillis SL, Joudi FN. Gleason score and laterality concordance between prostate biopsy and prostatectomy specimens. Int Braz J Urol 2009;35:559-564.

12. Tuygun $C$, Demirel F, Yigitbasi O, Bozkurt H, Bakirtas $\mathrm{H}$, İmamoglu A. Comparison of Gleason scores in specimens of transrectal prostate needle biopsy and radical prostatectomy. UHOD 2009;3:129-133.

13. Bulbul MA, El-Hout $Y$, Haddad $M$, et al. Pathological correlation between needle biopsy and radical prostatectomy specimen in patients with localized prostate cancer. Can Urol Assoc J 2007;1:264-266.

14. Fukagai $T$, Namiki $T$, Namiki $H$, Carlile RG, Shimada M, Yoshida H. Discrepancies between Gleason scores of needle biopsy and radical prostatectomy specimens. Pathol Int 2001;51:364-370.

15. Kayano PP, Carneiro A, Castilho TML, et al. Comparison of Gleason upgrading rates in transrectal ultrasound systematic random biopsies versus US-MRI fusion biopsies for prostate cancer. Int Braz J Urol 2018;44:11061113.

16. Jones TA, Radtke JP, Hadaschik B, Marks LS. Optimizing safety and accuracy of prostate biopsy. Curr Opin Urol 2016;26:472-480.

17. Demirtas A, Sonmez G, Tombul ST, Demirtas $\mathrm{T}$, Akgun H. Comparison of the Upgrading Rates of International Society of Urological Pathology Grades and Tumor Laterality in Patients Undergoing Standard 12-Core Prostate Biopsy versus Fusion Prostate Biopsy for Prostate Cancer. Urol Int 2019;103:256-261.

18. Corcoran NM, Hong MK, Casey RG, et al. Upgrade in Gleason score between prostate biopsies and pathology following radical prostatectomy significantly impacts upon the risk of biochemical recurrence. BJU Int 2011;108:E202-210.

19. Helpap B, Egevad L. The significance of modified Gleason grading of prostatic carcinoma in biopsy and radical prostatectomy specimens. Virchows Arch 2006;449:622-627.

20. Pereira RA, Costa RS, Muglia VF, et al. Gleason score and tumor laterality in radical prostatectomy and transrectal ultrasound-guided 
biopsy of the prostate: a comparative study. Asian J Androl 2015;17:815-820.

21. Dell'Atti L. Can transrectal ultrasound-guided biopsy of the prostate with extended 14-core scheme improve the predictive accuracy of Gleason score and tumor site in prostate cancer treatment? J BUON 2015;20:1239-1243.

22. Yeldir N, Yildiz E, Dundar G. Gleason score correlation between prostate needle biopsy and radical prostatectomy materials. Turk Patholoji Derg 2019;35:185-192.

23. Kim JJ, Kim T, Lee $\mathrm{H}$, et al. Prediction of unilateral prostate cancer by the combination of transrectal ultrasonography-guided prostate biopsy and multi-parametric magnetic resonance imaging: A real-life experience. PLoS One 2018;13:e202872. 